\title{
The Farnesyltransferase Inhibitors Tipifarnib and Lonafarnib Inhibit Cytokines Secretion in a Cellular Model of Mevalonate Kinase Deficiency
}

\author{
ANNALISA MARCUZZI, LUIGINA DE LEO, GIULIANA DECORTI, SERGIO CROVELLA, ALBERTO TOMMASINI, \\ AND ALESSANDRA PONTILLO
}

\begin{abstract}
Medical Genetic Service [A.M., S.C., A.P.], Laboratory of Immunopathology [A.T.], Institute for Maternal and Child Health "Burlo Garofolo," Trieste 34134, Italy; Department of Reproductive and Developmental Sciences and Public Health Care [L.D.L.], Department of Life Sciences [G.D.], University of Trieste, Trieste 34137, Italy; Department of Genetics [S.C.], Federal University of Pernambuco, Cidade Universitaria, 50.740-530 Recife, Brazil
\end{abstract}

\begin{abstract}
The shortage of geranylgeranyl-pyrophosphate (GGPP) was associated to an increased IL-1 $\beta$ release in the autoinflammatory syndrome mevalonate kinase deficiency (MKD), a rare inherited disease that has no specific therapy. Farnesyltransferase inhibitors (FTIs) act at the end of mevalonate pathway. Two FTIs, Tipifarnib (Tip) and Lonafarnib (Lon), were therefore evaluated as possible therapeutical choices for the treatment of MKD. FTIs could lead to a redirection of the limited available number of mevalonate intermediates preferentially to GGPP synthesis, eventually preventing the uncontrolled inflammatory response. The effect of Tip and Lon on intracellular cholesterol level (ICL) and on proinflammatory cytokines secretion was evaluated in a cellular model of MKD, chemically obtained treating RAW 264.7 cells with lovastatin (Lova) and alendronate (Ald). The combination of FTIs with the isoprenoid geraniol $(\mathrm{GOH})$ was also tested both in this model and in monocytes isolated from MKD patients. Tip and Lon proved to revert the ICL lowering and to significantly reduce the lipopolysaccharide-induced cytokines secretion in Ald-Lova -RAW 264.7 cells. This antiinflammatory effect was amplified combining the use of $\mathrm{GOH}$ with FTIs. The effect of GOH and Tip was successfully replicated in MKD patients' monocytes. Tip and Lon showed a dramatic antiinflammatory effect in monocytes where mevalonate pathway was chemically or genetically impaired. (Pediatr Res 70: 78-82, 2011)
\end{abstract}

$I^{n}$ $\mathrm{n}$ the familial mevalonate kinase deficiency (MKD, OMIM: *251170), the second enzyme of the mevalonate pathway [mevalonate kinase, $\mathrm{MK} / \mathrm{mevalonate}$ kinase gene (NM_000431) $(M V K)]$ is mutated and shows a reduced activity, leading to a shortage of downstream compounds. In particular, the lack of geranylgeranyl-pyrophosphate (GGPP) results in an augmented caspase-1-dependent IL- $1 \beta$ secretion that is the major cytokine responsible for the inflammatory systemic effects observed in MKD patients $(1,2)$. These subjects present periodic fever attacks associated with lymphadenopathy, abdominal, articular, and cutaneous involvement, and, in most severe cases, also neurological impairment (3). Despite the many efforts done in the past decades to elucidate

Received October 7, 2010; accepted January 12, 2011

Correspondence: Annalisa Marcuzzi, Ph.D., Medical Genetic Service, Institute for Maternal and Child Health "Burlo Garofolo," Via dell'Istria 65/1, 34134 Trieste, Italy; e-mail: marcuzzi@burlo.trieste.it

Supported by a grant from the Institute for Maternal and Child Health IRCCS "Burlo Garofolo," Italy (RC 13/2008). the molecular events linking the mevalonate pathway impairment to the inflammatory clinical phenotype, no specific treatment has been yet developed for MKD.

We and other authors have recently proposed natural exogenous isoprenoids (NEIs) as a possible therapeutic approach for MKD. These compounds, because of their isoprenoid structure, are supposed to enter the mevalonate pathway and to bypass the biochemical block, reconstituting the pathway and limiting the shortage of GGPP $(2,4,5)$ (Fig. 1).

With similar results, the farnesyltransferase inhibitor (FTI) Manumycin A (ManA) was recently used in our cellular and murine model of MKD (6). FTIs are a class of experimental drugs that target protein FT with the downstream effect of preventing the proper functioning of Ras protein, and they have been studied as anticancer agents but have not been definitely approved yet $(7,8)$. In our opinion, FT inhibition in MKD cells lead to a redirection of the limited available number of GGPP molecules preferentially to geranylgeranylation, thereby preventing the activation of caspase- 1 and production of mature IL1 $\beta$ (Fig. 1).

Taking into account all these findings, and in particular those obtained with ManA, we decided to investigate the effect of two novel FTIs, Tipifarnib (Tip) and Lonafarnib (Lon) $(9,10)$, on the inflammation induced by the inhibition of the mevalonate pathway, in the hypothesis to find out an alternative use for these anticancer drugs in the treatment of MKD (Fig. 1).

Tip and Lon were first tested in a cellular model of MKD obtained treating the murine monocytic cell lines RAW 264.7 with two known inhibitors of the mevalonate pathway, alendronate (Ald) (11) and lovastatin (Lova) (12), and then in monocytes isolated from two MKD patients. The cellular model obtained with the combined use of Ald and Lova aims

Abbreviations: Ald, alendronate; FTIs, farnesyltransferase inhibitors; GGPP, geranylgeranyl-pyrophosphate; GOH, geraniol; ICL, intracellular cholesterol level; Lon, Lonafarnib, Sarasar; Lova, lovastatin; LPS, lipopolysaccharide; ManA, Manumycin A; MK, mevalonate kinase (E.C. 2.7.1.36); MKD, mevalonate kinase deficiency; MTT, 3-(4.5-dimethylthiazol-2-yl)-2.5diphenyltetrazolium bromide; $\boldsymbol{M V K}$, mevalonate kinase gene (NM_000431); NEIs, natural exogenous isoprenoids; Tip, Tipifarnib, Zarnestra 


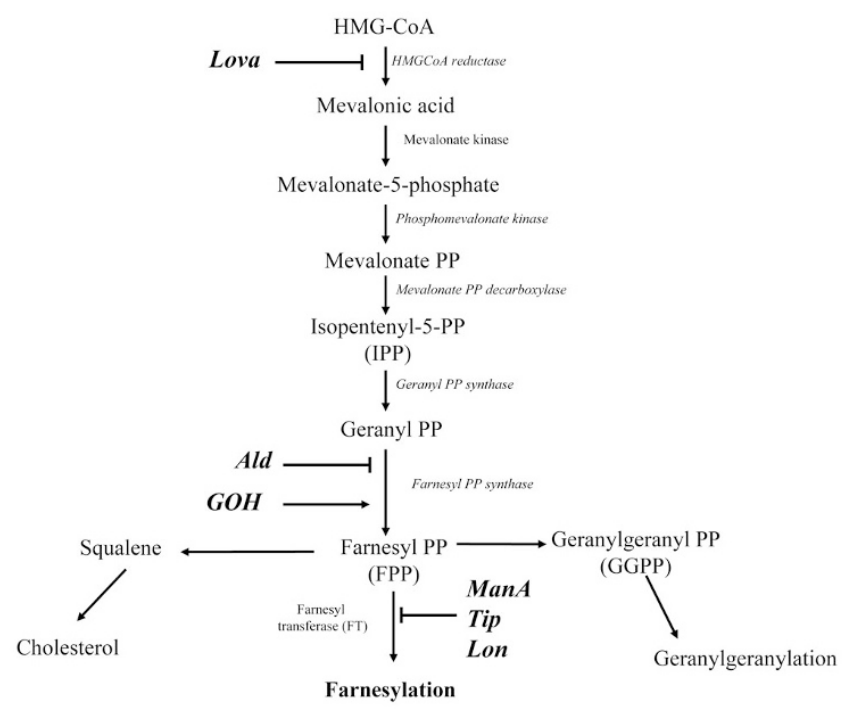

Figure 1. Schematic representation of mevalonate pathway. Compounds used in the experiments are indicated along the pathway in bold characters.

to reproduce as faithfully as possible the condition of block metabolic pathway of cholesterol. The results were compared with those obtained with NEIs for their anti-inflammatory action that has been recently described in these models $(6,13)$ : finally, we evaluated the additive effect of FTIs and NEIs.

\section{MATERIALS AND METHODS}

Chemicals. Lipopolysaccharide (LPS, E. coli-serotype 055:B5, $1 \mathrm{mg} / \mathrm{mL}$ stock in $\left.\mathrm{H}_{2} \mathrm{O}\right)$, Ald $(30 \mathrm{mM})$, geraniol $(\mathrm{GOH}, 6 \mathrm{M}$; Euphar group s.r.l., Piacenza, Italy), and Lova $(50 \mathrm{mM})$ were dissolved in saline solution. ManA $(10 \mu \mathrm{M})$, Tip (Tip, $20 \mathrm{mM})$, and Lon $(16.5 \mathrm{mM})$ were dissolved in DMSO so that the final concentration of DMSO would not exceed $0.1 \%$. Tip (Tip, R115777, Zarnestra) and Lon (SCH66336, Sarasar) were kindly provided by Prof G. Martinelli (Institute of Hematology 'L and A Seràgnoli', University of Bologna, Bologna, Italy). All the reagents were from Sigma Chemical Co.-Aldrich (Milan, Italy), except where differently specified.

RAW 264.7 cell culture. RAW 264.7 cells (murine monocyte/macrophage cell line) were cultured in DMEM supplemented with $10 \%$ fetal bovine serum with $100 \mu \mathrm{M}$ Ald and $20 \mu \mathrm{M}$ Lova for $20 \mathrm{~h}$ and then with $10 \mu \mathrm{g} / \mathrm{mL}$ LPS for additional $24 \mathrm{~h}$. At the end of the incubation period, the supernatants were collected for cytokine evaluation, while the cells were pelleted for the quantification of intracellular cholesterol. In the experiments, GOH $(100 \mu \mathrm{M})$, ManA $(10 \mu \mathrm{M})$, Tip $(5 \mu \mathrm{M})$, or Lon $(5 \mu \mathrm{M})$ were added together with Ald and Lova.

MKD patients and monocyte isolation. Monocytes isolated from the peripheral blood of two MKD subjects (patient 1, P1: 4 y old, male, $M V K$ : S135L/V377I; patient 2, P2: 10 y old, male, MVK: I268T/V377I), through standard protocol, were cultured at a cell density of $2 \times 10^{5}$ cells/well in RPMI 1640 containing 10\% fetal bovine serum (Euroclone, Milan, Italy). Cells were incubated with $10 \mu \mathrm{M} \mathrm{GOH}$ for $20 \mathrm{~h}$, or $5 \mu \mathrm{M}$ Tip for $1 \mathrm{~h}$, or their combination. Cells were then treated with $1 \mu \mathrm{g} / \mathrm{mL}$ LPS for supplementary $24 \mathrm{~h}$. At the end of the incubation period, the supernatants were collected for IL1 $\beta$ assay. Written informed consent was obtained from patients' parents, according to the protocol of the ethical board of Institute of Children Health "Burlo Garofolo" (Trieste, Italy; n.185/08, 19/08/2008).

Determination of cytokines release (IL1 $\beta, I L 18$, and TNF $\alpha)$. IL1 $\beta$, IL18, and TNF $\alpha$ concentrations were determined in the cell culture medium (supernatant) by ELISA kits according to manufacturer's protocols, and the amount of cytokines expressed as picograms per milliliters (Endogen Human IL-1 $\beta$ ELISA Kit; Pierce Biotechnology Inc., Rockford, IL).

Determination of intracellular free cholesterol. The amount of free cholesterol was determined with the Amplex red cholesterol assay kit according to the manufacturer's instructions (Molecular Probes, Invitrogen), and the amount of cholesterol expressed as micrometers $(14,15)$.

Evaluation of cytotoxicity. Tip, Lon, ManA, and GOH toxicity were evaluated with the MTT (3-(4.5-dimethylthiazol-2-yl)-2.5-diphenyltetrazolium bromide) assay according to the method of Mosmann (16). Briefly, $2 \times$
$10^{5} / \mathrm{mL}$ RAW 264.7 cells or human monocytes were incubated with 10 to 200 $\mu \mathrm{M}$ Ald, 5 to $40 \mu \mathrm{M}$ Lova, 1 to $50 \mu \mathrm{g} / \mathrm{mL}$ LPS, 1 to $20 \mu \mathrm{M}$ Tip, 1 to $20 \mu \mathrm{M}$ Lon, 1 to $20 \mu \mathrm{M}$ ManA, and GOH 10 to $100 \mu \mathrm{M}$ alone and in combination, for $3 \mathrm{~d}$; before adding MTT reagent.

Statistical analysis. All results are expressed as the mean \pm SE. Statistical significance was calculated using one-way ANOVA, followed by Tukey multiple comparison test. $p$ values less than 0.05 were considered significant. Statistical analysis was performed using the GraphPad Prism software version 5 (GraphPad Software, San Diego, CA).

\section{RESULTS}

Tip $(1-20 \mu \mathrm{M})$ or Lon $(1-20 \mu \mathrm{M})(9,17,18)$ were added to the cellular model of MKD obtained treating RAW 264.7 cells simultaneously with $100 \mu \mathrm{M}$ Ald and $20 \mu \mathrm{M}$ Lova. Ald + Lova lead to a significantly reduction of intracellular cholesterol level (ICL; $10.43 \pm 1.12 \mu \mathrm{M}$ ) when compared with untreated cells $(14.40 \pm 0.72 \mu \mathrm{M})$ as expected being inhibitors of mevalonate pathway; this inhibition was amplified in the presence of LPS (Ald + Lova + LPS: $7.88 \pm 0.28 \mu \mathrm{M}$ ). In Figure 2, the effect of $5 \mu \mathrm{M}$ Tip and $5 \mu \mathrm{M}$ Lon was reported as minor dose with maximum results. We tested several concentration of both compounds and finally we chose the dose of $5 \mu \mathrm{M}$ according to indication in literature data. The DMSO used as solvent for the two compounds did not alter any of the results (data not showed).

Tip and Lon were able to significantly revert the diminishing of ICL $(9.70 \pm 0.17 \mu \mathrm{M}$ and $9.76 \pm 0.40 \mu \mathrm{M}$, respectively) compared with Ald + Lova + LPS. These results were comparable with those obtained with $\operatorname{ManA}(9.53 \pm 0.56 \mu \mathrm{M})$ and $\mathrm{GOH}(9.6 \pm 0.69 \mu \mathrm{M})$.

The secretion in the cell culture medium of proinflammatory cytokines IL1 $\beta$, IL18, and TNF were significantly reduced in Ald-Lova-LPS cells treated with Tip and Lon (Table 1). In Figure 3, the effect of Tip $(5 \mu \mathrm{M})$ and Lon $(5 \mu \mathrm{M})$ on IL1 $\beta$ reduction was reported as exemplificative of the three cytokines. Similar reductions (Tip: $44.3 \%$; Lon: $46 \%$ ) were obtained with the natural isoprenoid $\mathrm{GOH}(54.3 \%)$ or with another FTI, ManA (32.3\%; Fig. 3). The cytokine release to

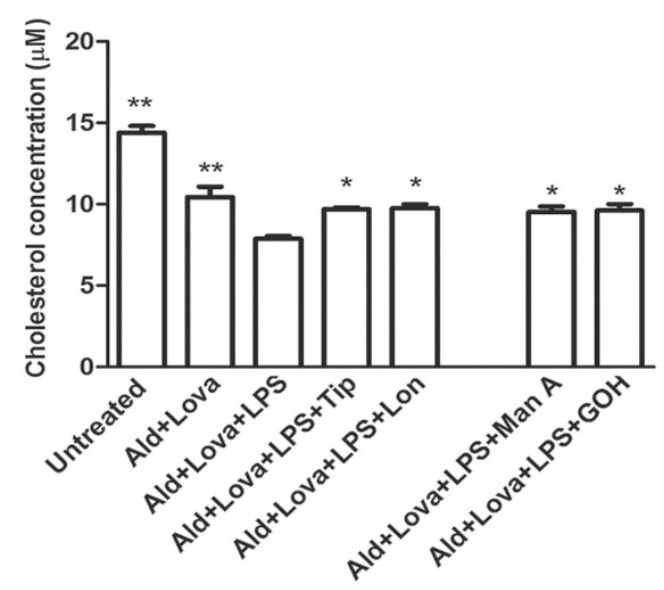

Figure 2. Tipifarnib and Lonafarnib rescue the levels of intracellular cholesterol in Ald-Lova-LPS RAW 264.7 cells. Cells were incubated with 100 $\mu \mathrm{M}$ alendronate (Ald) and $20 \mu \mathrm{M}$ lovastatin (Lova) for $20 \mathrm{~h}$, and then with $10 \mu \mathrm{g} / \mathrm{mL}$ LPS for supplementary $24 \mathrm{~h}$. Bars represent the means ICL $(\mu \mathrm{M}) \pm \mathrm{SE}$ of three independent experiments. ${ }^{*} p<0.05$ significantly different from ICL in Ald + Lova + LPS-treated cells. $* * p<0.01$ significantly different from ICL in Ald + Lova + LPS-treated cells. 
Table 1. Effect of Tipifarnib (Tip), Lonafarnib (Lon), Manumycin A (ManA), and Geraniol (GOH) on LPS-induced cytokines secretion in Ald-Lova-LPS RAW 264.7 cells

\begin{tabular}{|c|c|c|c|c|c|c|c|c|c|}
\hline & $\begin{array}{c}\text { Ald + Lova } \\
+ \text { LPS }\end{array}$ & $\begin{array}{c}\text { Ald + Lova }+ \\
\text { LPS + Tip }\end{array}$ & $p$ & $\begin{array}{c}\text { Ald + Lova }+ \\
\text { LPS + Lon }\end{array}$ & $p$ & $\begin{array}{l}\text { Ald + Lova + } \\
\text { LPS + ManA }\end{array}$ & $p$ & $\begin{array}{c}\text { Ald + Lova + } \\
\text { LPS + GOH }\end{array}$ & $p$ \\
\hline $\mathrm{IL}-1 \beta(\mathrm{pg} / \mathrm{mL})$ & $5506 \pm 675.2$ & $3291 \pm 401.7$ & $<0.01 *$ & $1567 \pm 243.1$ & $<0.01 *$ & $2673 \pm 305.8$ & $<0.01 *$ & $2673 \pm 305.8$ & $<0.05 \dagger$ \\
\hline IL-18 (pg/mL) & $1297 \pm 135.2$ & $790.5 \pm 112.5$ & $<0.01 *$ & $628 \pm 49.47$ & $<0.01 *$ & $611.6 \pm 6.3$ & $<0.01 *$ & $611.6 \pm 6.3$ & $<0.01 *$ \\
\hline $\mathrm{TNF}-\alpha(\mathrm{pg} / \mathrm{mL})$ & $7260 \pm 329.1$ & $3456 \pm 78.42$ & $<0.01^{*}$ & $1690 \pm 10.15$ & $\begin{array}{l}<0.01 * \\
<0.05 \dagger\end{array}$ & $2329 \pm 195.2$ & $<0.01 *$ & $2329 \pm 195.2$ & $<0.01 *$ \\
\hline
\end{tabular}

Data were representative of three distinct experiments. Mean concentration and SE are reported.

* Significantly different from cytokine concentration in Ald-Lova-LPS cells.

$\dagger$ Significantly different from cytokine concentration in Ald-Lova-LPS cells.

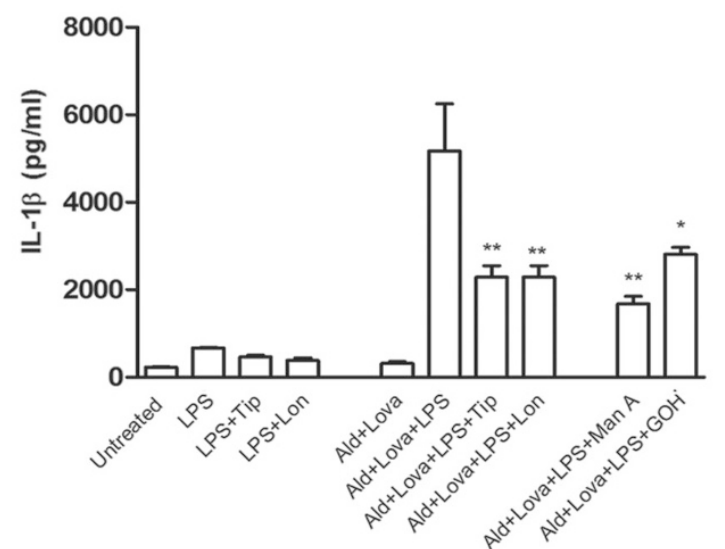

Figure 3. Tipifarnib and Lonafarnib are able to lower the IL- $1 \beta$ secretion in Ald-Lova-LPS RAW 264.7 cells. Cells were incubated with $100 \mu \mathrm{M}$ alendronate (Ald) and $20 \mu \mathrm{M}$ lovastatin (Lova) for $20 \mathrm{~h}$, and then with $10 \mu \mathrm{g} / \mathrm{mL}$ LPS for supplementary $24 \mathrm{~h}$ (Ald + Lova + LPS). FTIs (10 $\mu \mathrm{M}$ ManA, $5 \mu \mathrm{M}$ Tip, $5 \mu \mathrm{M}$ Lon $)$ and GOH $(100 \mu \mathrm{M})$ were added simultaneously with Ald and Lova. Bars represent the mean concentration $(\mathrm{pg} / \mathrm{mL}) \pm \mathrm{SE}$ of three experiments. $* p<0.05$ significantly different from cytokine concentration in Ald-Lova-LPS cells. **p $<0.01$ significantly different from cytokine concentration in Ald-Lova-LPS cells.

the untreated cells $(230 \pm 20 \mathrm{pg} / \mathrm{mL})$ and in presence of Ald and Lova $(316 \pm 20 \mathrm{pg} / \mathrm{mL})$ alone can be seen in the Figure 3. Tip and Lon were able to rescue the IL- $1 \beta$ secretion compared with LPS-treated cells even if not in a statistically significant way (Fig. 3). When GOH was used together with Tip and Lon, the effect of the two FTIs on the IL1 $\beta$, IL18, and TNF secretion was amplified (Table 2 ) as reported in Figure 4 for IL1 $\beta$.

Tip + GOH and Lon + GOH significantly diminish IL1 $\beta$ secretion $(277.1 \pm 92.1 \mathrm{pg} / \mathrm{mL}$ and $421.9 \pm 122.5 \mathrm{pg} / \mathrm{mL}$, respectively) when compared with Ald + Lova + LPS-treated cells $(5519 \pm 1497 \mathrm{pg} / \mathrm{mL} ; p<0.05)$ as well as to Tip (2291 $\pm 453.2 \mathrm{pg} / \mathrm{mL} ; p<0.05)$, Lon $(2305 \pm 359.8 \mathrm{pg} / \mathrm{mL}$; $p<0.05)$, or GOH $(2811 \pm 271.1 \mathrm{pg} / \mathrm{mL} ; p<0.05)$ alone (Fig. 4). A similar additive anti-inflammatory effect was also observed using GOH combined with ManA (Fig. 4).

The combination Tip $+\mathrm{GOH}$ resulted significantly more effective than Lon $+\mathrm{GOH}(p<0.001)$, and so we decided to test Tip, GOH, and Tip + GOH on LPS-induced IL-1 $\beta$ secretion in monocytes isolated from two MKD patients. In MKD patient 1 (P1), Tip was more effective in diminishing IL-1 $\beta$ secretion compared with LPS-treated cells alone or in combination with $10 \mu \mathrm{M}$ GOH even if not in a statistically significant way (Tip + LPS $107.8 \pm 32.8 \mathrm{pg} / \mathrm{mL}$; Tip +
$\mathrm{GOH}+\mathrm{LPS} 92.36 \pm 0.47 \mathrm{pg} / \mathrm{mL}$ versus $\mathrm{LPS} 171.9 \pm 11.6$ $\mathrm{pg} / \mathrm{mL}$ : p; Fig. $5 A$ ). This effect was registered also in MKD patient 2 (P2): Tip and Tip + GOH significantly reduced LPS-induced IL- $1 \beta$ secretion in (P2) (Tip + LPS $273.3 \pm 9.2$ $\mathrm{pg} / \mathrm{mL}$, Tip $+\mathrm{GOH}+$ LPS $188.2 \pm 20.5 \mathrm{pg} / \mathrm{mL}$ versus $\mathrm{LPS}$ $1068 \pm 92.7$ pg/mL: $\mathrm{p}<0.001$; Fig. 5B). Tip and Lon, at the concentration used, did not result cytotoxic when evaluated with the MTT assay (data not shown).

\section{DISCUSSION}

The inhibition of farnesyltransferase is nowadays a common target for antineoplastic drugs because of the consequent reduction of farnesylated protein such as small GTP proteins of oncogene Ras family (19). Recently, we reported the use of the FTI ManA as a possible choice for the treatment of the hereditary rare and still orphan disease MKD (6). The hypothesized mechanism of FTIs is principally related to the redirection of GGPP to geranylgeranylation (6).

In this study, we decided to investigate the effect of other two FTIs, the Tip and Lon, that are currently used in clinical trial $(20,21)$ in a MKD cellular model because in our opinion, they could be more easily and rapidly included in the treatment of other inflammatory diseases.

In this cellular model, the combination of Ald and Lova induced an expected and significant reduction in intracellular cholesterol, similarly to what shown in mice serum level (22), and let us using this parameter to verify the changes in mevaloante pathway induced by different compounds (isoprenoids or FTIs).

Tip and Lon were able to revert the decrease of intracellular cholesterol induced by Lova and Ald (Fig. 2; inhibitors of HMG-CoA-red and farnesyl-pyrophosphate synthase, respectively, as shown in Fig. 1), demonstrating that these compounds, acting on FT, could modulate the outcome of the residual intermediates of mevalonate pathway below farnesylpyrophosphate synthase driving them through the other two main exits, cholesterol biosynthesis and geranylgeranylation.

Moreover, these FTIs reduced proinflammatory cytokines secretions either in MKD cellular model (Fig. 3) and in monocytes isolated from MKD patients (Fig. 5), emphasizing the hypothesis that the reequilibration of GGPP production could ameliorate the inflammatory state because of a biochemical or a familial unpaired mevalonate pathway (6). Similar results were previously obtained through the use of exogenous isoprenoids, such as GOH, farnesol, and geranylGOH $(4,13)$, 
Table 2. Geraniol (GOH) enhances the anti-inflammatory effect of farnesyltransferase inhibitors (Tipifarnib, Lonafarnib, and Manumycin A)

\begin{tabular}{|c|c|c|c|c|c|}
\hline & $\begin{array}{l}\text { Ald + Lova + } \\
\text { LPS + GOH }\end{array}$ & $\begin{array}{l}\text { Ald }+ \text { Lova }+ \\
\text { LPS + Tip }\end{array}$ & $\begin{array}{c}\text { Ald + Lova + LPS + } \\
\text { GOH + Tip }\end{array}$ & $\mathrm{P} 1$ & $\mathrm{P} 2$ \\
\hline $\mathrm{IL}-1 \beta(\mathrm{pg} / \mathrm{mL})$ & $2811 \pm 157.1$ & $3291 \pm 401.7$ & $310.6 \pm 72.37$ & $p<0.05$ & $p<0.05$ \\
\hline IL-18 (pg/mL) & $730.6 \pm 17.77$ & $790.5 \pm 112.5$ & $132.5 \pm 25.76$ & $p<0.05$ & $p<0.05$ \\
\hline \multirow[t]{2}{*}{$\mathrm{TNF}-\alpha(\mathrm{pg} / \mathrm{mL})$} & $1841 \pm 44.84$ & $3456 \pm 78.42$ & $446.1 \pm 3.45$ & $p<0.01$ & $p<0.01, p<0.05$ \\
\hline & $\begin{array}{l}\text { Ald + Lova + } \\
\text { LPS + GOH }\end{array}$ & $\begin{array}{l}\text { Ald + Lova + } \\
\text { LPS + Lon }\end{array}$ & $\begin{array}{c}\text { Ald }+ \text { Lova }+ \text { LPS }+ \\
\text { GOH }+ \text { Lon }\end{array}$ & P3 & P4 \\
\hline $\mathrm{IL}-1 \beta(\mathrm{pg} / \mathrm{mL})$ & $2811 \pm 157.1$ & $1567 \pm 243.1$ & $321.9 \pm 18.92$ & $p>0.05$ & $p>0.05$ \\
\hline IL-18 (pg/mL) & $730.6 \pm 17.77$ & $628 \pm 49.47$ & $95.60 \pm 5.3$ & $p<0.01$ & $p<0.05$ \\
\hline \multirow[t]{2}{*}{ TNF- $\alpha(\mathrm{pg} / \mathrm{mL})$} & $1841 \pm 44.84$ & $1690 \pm 10.15$ & $777.3 \pm 0.54$ & $p<0.05$ & $p>0.05$ \\
\hline & $\begin{array}{l}\text { Ald + Lova + } \\
\text { LPS + GOH }\end{array}$ & $\begin{array}{c}\text { Ald + Lova + } \\
\text { LPS + ManA }\end{array}$ & $\begin{array}{c}\text { Ald }+ \text { Lova }+ \text { LPS }+ \\
\text { GOH }+ \text { ManA }\end{array}$ & P5 & P6 \\
\hline $\mathrm{IL}-1 \beta(\mathrm{pg} / \mathrm{mL})$ & $2811 \pm 157.1$ & $2673 \pm 305.8$ & $264.5 \pm 3.94$ & $p>0.05$ & $p>0.05$ \\
\hline IL-18 (pg/mL) & $730.6 \pm 17.77$ & $611.6 \pm 6.3$ & $118.9 \pm 13.88$ & $p<0.01$ & $p<0.05$ \\
\hline TNF- $\alpha(\mathrm{pg} / \mathrm{mL})$ & $1841 \pm 44.84$ & $2329 \pm 195.2$ & $394.1 \pm 81.49$ & $p<0.01$ & $p<0.01$ \\
\hline
\end{tabular}

Data were representative of three distinct experiments. Mean concentration and SE are reported.

P1, $p$ value of the comparison between Ald + Lova + LPS + GOH + Tip respect and ALD + Lova + LPS + GOH; P2, $p$ value of the comparison between Ald + Lova + LPS + GOH + Tip respect and ALD + Lova + LPS + Tip; P3, $p$ value of the comparison between Ald + Lova + LPS + GOH + Lon respect and ALD + Lova + LPS + GOH; P4, $p$ value of the comparison between Ald + Lova + LPS + GOH + Lon respect and ALD + Lova + LPS + Lon; P5, $p$ value of the comparison between Ald + Lova + LPS + GOH + ManA respect and ALD + Lova + LPs + GOH; P6, $p$ value of the comparison between Ald + Lova + LPS + GOH + ManA respect and ALD + Lova + LPS + ManA.

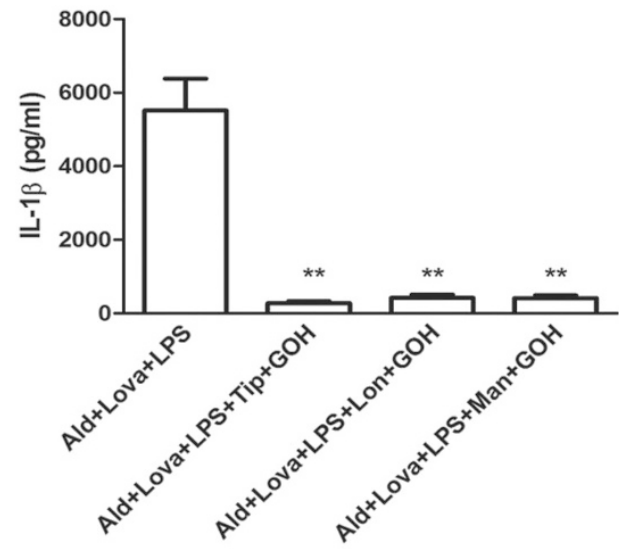

Figure 4. GOH enhances the anti-inflammatory effect of FTIs. Cells were incubated with $100 \mu \mathrm{M}$ alendronate (Ald) and $20 \mu \mathrm{M}$ lovastatin (Lova) (Ald + Lova) for $20 \mathrm{~h}$, and then with $10 \mu \mathrm{g} / \mathrm{mL}$ LPS for supplementary $24 \mathrm{~h}$. FTIs (10 $\mu \mathrm{M}$ ManA, $5 \mu \mathrm{M}$ Tip, $5 \mu \mathrm{M}$ Lon) and $100 \mu \mathrm{M}$ GOH were added simultaneously with Ald and Lova. Bars represent the mean concentration $(\mathrm{pg} / \mathrm{mL}) \pm \mathrm{SE}$ of three experiments. $* * p<0.01$ significantly different from cytokine concentration in Ald-Lova-LPS cells.

and they were replicated with GOH in this study to compare the two different anti-inflammatory approaches.

It seems that the anti-inflammatory effect of Tip and Lon, as well as of $\mathrm{GOH}$, was independent from the type of secreted cytokine, IL-1 $\beta$, IL-18, or TNF, indicating a mechanism acting before the specific and different inflammatory signaling pathways. IL-1 $\beta$ and IL-18 were produced after the caspase-1 activation, an event specifically induced by the inhibition of mevalonate pathway as reported by Mandey et al (2). For what concern the inhibition on TNF secretion, no theory has been yet proposed, even if previous works showed that the block of mevalonate pathway induced TNF secretion from monocytes underling the causative link between cholesterol metabolism
A
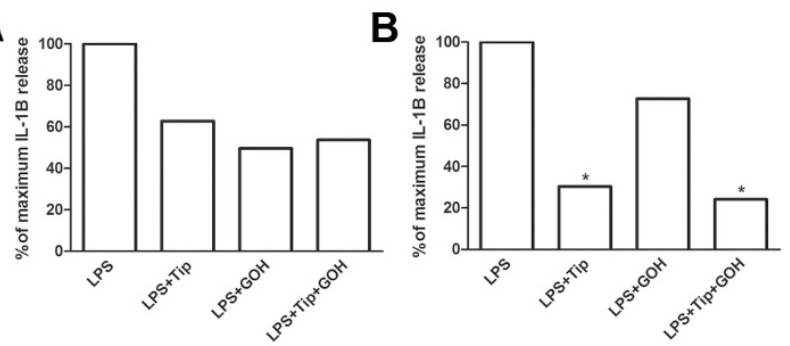

Figure 5. Tipifarnib, alone or in combination with $\mathrm{GOH}$, is able to lower the LPS-induced IL- $1 \beta$ secretion in MKD monocytes. LPS-induced IL- $1 \beta$ secretion in monocytes from two MKD patients (P1-4A; P2-4B) incubated in the absence or presence of $10 \mu \mathrm{M} \mathrm{GOH}$ for $20 \mathrm{~h}$, or $5 \mu \mathrm{M}$ Tip for $1 \mathrm{~h}$, or their combination. Cells were then treated $1 \mu \mathrm{g} / \mathrm{mL}$ LPS for supplementary $20 \mathrm{~h}$. Absolute values $(\mathrm{pg} / \mathrm{mL})$ were obtained from one experiment performed in triplicate. ${ }^{*} p<0.05$ significantly different from absolute value of cytokine concentration in LPS cells (100\%).

and TNF (23). We hypothesize that a small GTP protein or a prenilated protein could be involved in the signaling leading to TNF production, similarly to what happens with the activation of caspase-1 (2).

We first tried, unsuccessfully, to decrease the cytokines secretions to the basal condition with augmenting concentration of both FTIs and $\mathrm{GOH}$, considering their similar antiinflammatory effect (data not shown). We then tried with the combination of Tip or Lon and GOH: this significantly reduced the cytokines production (Fig. 4). Beyond expectation, FTIs and GOH showed a synergic effect, probably related to the bypassing of a compensative dose-related mechanism induced by each single compound, or alternative to the different mechanism of action of FTIs and GOH.

Our results suggest that the manipulation of the mevalonate pathway through the use of FTIs or GOH with the purpose to rebalance the intermediates levels acts above and in an aspe- 
cific mechanism. Tip used in monocytes isolated from two MKD patients showed interesting results (Fig. 5) even if a certain interindividual variability and the limited number of patients did not allow us to definitively demonstrate the efficacy ex vivo of this compound.

The different entity of response between the two patients could be explained taking in account the interaction between genetic defect and compounds concentration. In MKD, residual MK activity varies from $<0.5$ to $7 \%$ depending on the type of $M V K$ mutations (24). Considering that MK activity affects the levels of GGPP and the consequent shortage of geranylgeranylation, monocytes from subjects carrying different MVK mutations could need different amount of Tip to exhibit the same anti-inflammatory effect. A quantitative residual MK activity evaluation was not performed in our patients because it is quite expensive and not so informative for the clinical follow-up, but the possible residual MK activity could at least in part explain the different response to isoprenoids in the two patients carrying different mutations.

In conclusion, in agreement with previously reported data $(2,4,6)$, our findings suggest once more that the recovery of GGPP flux through the geranylgeranyltransferase, in this case through the use of Tip and Lon, has an anti-inflammatory effect, both in pharmacologic or in genetic blockage of the mevalonate pathway. These molecules are nowadays used in clinical protocols as anticancer drugs, so when considering our findings and those already reported in the literature, we would like to propose the use of Tip and Lon as a novel therapeutical approach for the still orphan disease MKD.

Acknowledgments. We thank Prof G. Martinelli and Dr. I. Iacobucci (Institute of Hematology 'L and A Seràgnoli', University of Bologna, Bologna, Italy) for giving us Tipifarnib and Lonafarnib.

\section{REFERENCES}

1. Kuijk LM, Mandey SH, Schellens I, Waterham HR, Rijkers GT, Coffer PJ, Frenkel J 2008 Statin synergizes with LPS to induce IL-1beta release by THP-1 cells through activation of caspase-1. Mol Immunol 45:2158-2165

2. Mandey SH, Kuijk LM, Frenkel J, Waterham HR 2006 A role for geranylgeranylation in interleukin-1beta secretion. Arthritis Rheum 54:3690-3695

3. Haas D, Hoffmann GF 2006 Mevalonate kinase deficiencies: from mevalonic aciduria to hyperimmunoglobulinemia D syndrome. Orphanet J Rare Dis 1:13

4. Marcuzzi A, Pontillo A, De Leo L, Tommasini A, Decorti G, Not T, Ventura A 2008 Natural isoprenoids are able to reduce inflammation in a mouse model of mevalonate kinase deficiency. Pediatr Res 64:177-182
5. Frenkel J, Rijkers GT, Mandey SH, Buurman SW, Houten SM, Wanders RJ, Waterham HR, Kuis W 2002 Lack of isoprenoid products raises ex vivo interleukinlbeta secretion in hyperimmunoglobulinemia D and periodic fever syndrome. Arthritis Rheum 46:2794-2803

6. De Leo L, Marcuzzi A, Decorti G, Tommasini A, Crovella S, Pontillo A 2010 Targeting farnesyl-transferase as a novel therapeutic strategy for mevalonate kinase deficiency: in vitro and in vivo approaches. Pharmacol Res 61:506-510

7. Appels NM, Beijnen JH, Schellens JH 2005 Development of farnesyl transferase inhibitors: a review. Oncologist 10:565-578

8. Sebti SM 2005 Protein farnesylation: implications for normal physiology, malignant transformation, and cancer therapy. Cancer Cell 7:297-300

9. Xue X, Lai KT, Huang JF, Gu Y, Karlsson L, Fourie A 2006 Anti-inflammatory activity in vitro and in vivo of the protein farnesyltransferase inhibitor tipifarnib. J Pharmacol Exp Ther 317:53-60

10. Basso AD, Mirza A, Liu G, Long BJ, Bishop WR, Kirschmeier P 2005 The farnesyl transferase inhibitor (FTI) SCH66336 (lonafarnib) inhibits Rheb farnesylation and mTOR signaling. Role in FTI enhancement of taxane and tamoxifen anti-tumor activity. J Biol Chem 280:31101-31108

11. Russell RG, Watts NB, Ebetino FH, Rogers MJ 2008 Mechanisms of action of bisphosphonates: similarities and differences and their potential influence on clinical efficacy. Osteoporos Int 19:733-759

12. Hilgendorff A, Muth H, Parviz B, Staubitz A, Haberbosch W, Tillmanns H, Holschermann H 2003 Statins differ in their ability to block NF-kappa B activation in human blood monocytes. Int J Clin Pharmacol Ther 41:397-401

13. Marcuzzi A, Tommasini A, Crovella S, Pontillo A 2010 Natural isoprenoids inhibit LPS-induced-production of cytokines and nitric oxide in aminobisphosphonatetreated monocytes. Int Immunopharmacol 10:639-642

14. Frey T, De Maio A 2007 Increased expression of CD14 in macrophages after inhibition of the cholesterol biosynthetic pathway by lovastatin. Mol Med 13:592604

15. Iftakhar-E-Khuda I, Koide N, Hassan F, Noman AS, Dagvadorj J, Tumurkhuu G, Naiki Y, Komatsu T, Yoshida T, Yokochi T 2009 Novel mechanism of U18666Ainduced tumour necrosis factor-alpha production in RAW 264.7 macrophage cells. Clin Exp Immunol 155:552-558

16. Mosmann T 1983 Rapid colorimetric assay for cellular growth and survival: application to proliferation and cytotoxicity assays. J Immunol Methods 65:55-63

17. Desrosiers RR, Cusson MH, Turcotte S, Beliveau R 2005 Farnesyltransferase inhibitor SCH-66336 downregulates secretion of matrix proteinases and inhibits carcinoma cell migration. Int J Cancer 114:702-712

18. O'Meara SJ, Kinsella BT 2005 The effect of the farnesyl protein transferase inhibitor SCH66336 on isoprenylation and signalling by the prostacyclin receptor. Biochem J 386:177-189

19. Braun T, Fenaux P 2008 Farnesyltransferase inhibitors and their potential role in therapy for myelodysplastic syndromes and acute myeloid leukaemia. Br J Haematol $141: 576-586$

20. Venkatasubbarao K, Choudary A, Freeman JW 2005 Farnesyl transferase inhibitor (R115777)-induced inhibition of STAT3(Tyr705) phosphorylation in human pancreatic cancer cell lines require extracellular signal-regulated kinases. Cancer Res 65:2861-2871

21. Baulch-Brown C, Molloy TJ, Yeh SL, Ma D, Spencer A 2007 Inhibitors of the mevalonate pathway as potential therapeutic agents in multiple myeloma. Leuk Res 31:341-352

22. Marcuzzi A, Decorti G, Pontillo A, Ventura A, Tommasini A 2010 Decreased cholesterol levels reflect a consumption of anti-inflammatory isoprenoids associated with an impaired control of inflammation in a mouse model of mevalonate kinase deficiency. Inflamm Res 59:335-338

23. Deng X, Yu Z, Funayama H, Yamaguchi K, Sasano T, Sugawara S, Endo Y 2007 Histidine decarboxylase-stimulating and inflammatory effects of alendronate in mice: involvement of mevalonate pathway, TNFalpha, macrophages, and T-cells. Int Immunopharmacol 7:152-161

24. Houten SM, Wanders RJ, Waterham HR 2000 Biochemical and genetic aspects of mevalonate kinase and its deficiency. Biochim Biophys Acta 1529:19-32 